\title{
THE EFFECT OF DIFFERENT TEMPERATURES DEGREES ON PRESERVATION PERIOD OF MEAT POULTRY
}

\author{
A. ARWANA* and KHALDON ALKOJA** \\ ${ }^{*}$ Professor of Meat. Hygiene, Faculty of Veterinary Medicine, Albaath University. \\ ** Eterinarian, Facultyof Veterinary Medicine, Albaath University. \\ Email: khaldon.koja@hotmail.com
}

\section{ABSTRACT}

Received at: $25 / 12 / 2013$

This study was included test of 90 chickens; 90 samples as (a chest) and 90

Accepted: 27/2/2014 samples as (as a thigh). These samples were divided into four categories: first one (consists of 45 chests) was stored with packages in a tin sheet, the second (45 chests) unpacked, the third (45 thighs) was stored with packages in a tin plate, the fourth (45 thighs) unpacked. Every sample of each category was divided into three groups. Every group consists of 15 . These groups were stored at $\left(25^{\circ}, 4+^{\circ}, 20-^{\circ}\right)$. Then $\mathrm{pH}$ and total count of bacteria were measured during storage in order to observe the time in which the samples will start to spoil in accordance with the Syrian Standards and Specifications Corporation 2007. We noticed the following physical changes: color, odor, flavor and texture. The results indicated to the spoilage of the thigh samples before the chest ones and the package samples before the unpackage ones. The samples spoiled after $24 \mathrm{~h}$ of storage at $25+^{\circ}$ and after 7 days of storage at $4+^{\circ}$, whereas the samples at $20-^{\circ}$ no spoilage was noticed but the appearance change after 6 months of storage was noticed. And packed was good effect on preservation samples at $20-^{\circ}$ Finally, the conclusions and the suggestions were written in order to guide the consumer in the field of poultry meat storage.

Key words: Temperatures, Preservation, Meat Poultry.

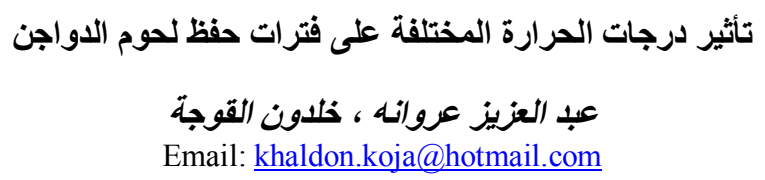

تضمنت الدر اسة فحص( • 9) فروج منها (• (9) عينة فروج (صدر دجاج كامل) و(· •9) عينة فروج (فخذ دجاج كامل) ثم قسمت العينات إلى أربع

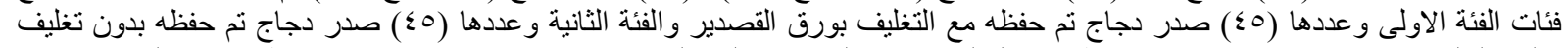

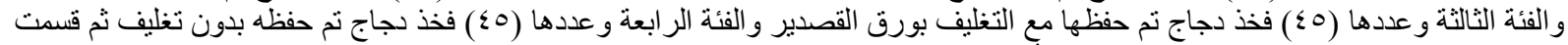

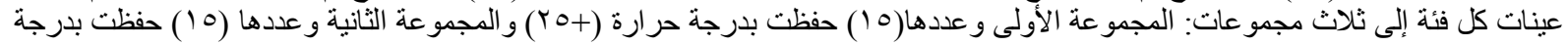

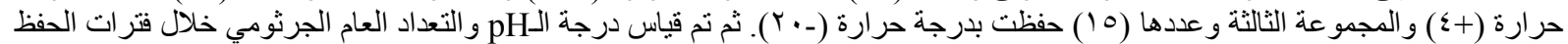

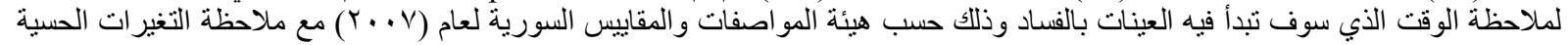

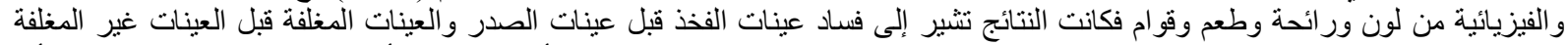

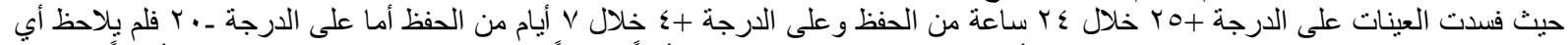

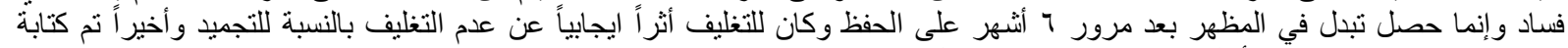

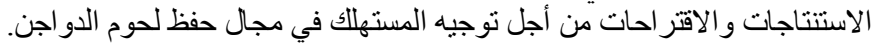

\section{INTRODUCTION}

المقدمــة

تعرف اللحوم على أنها الأجزاء الصالحة للاستهلاك الآدمي من الحيوانات المعدة للذبح والاستهلاك البشري وكذلك من الطيور والأسماك

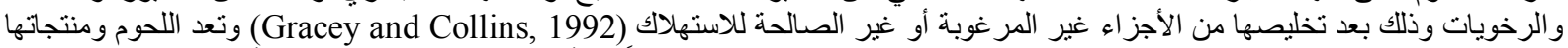

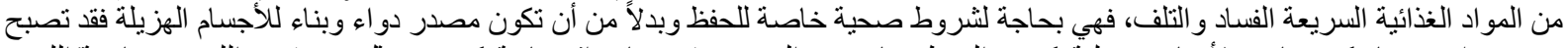

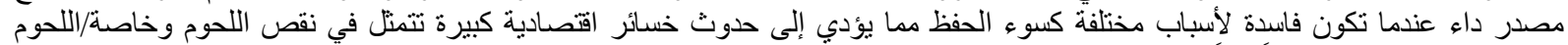

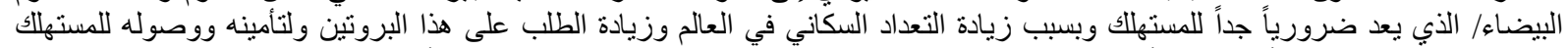

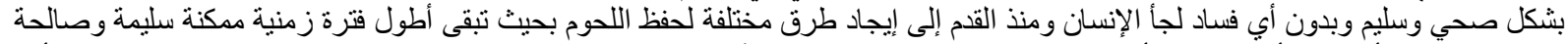
للاستهلاك بدون أي تغير أو فساد يطر أ عليها وخاصة عند نقلها من مكان لآخر (FAO, 1991) و إن عملية التبريد والتجميد هي واحدة من أهم 
الطرق الفعالة للإقلال من تكاثر ونمو مسببات الفساد الموجودة في اللحوم (Kiezmann et al.,1969) ويمكننا القول بأن التبريد والتجميد بساعدنا

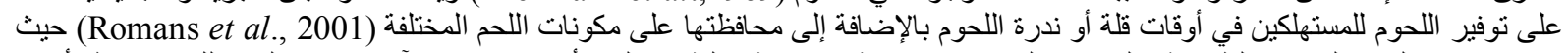

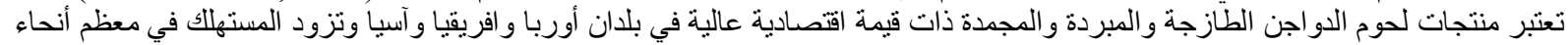

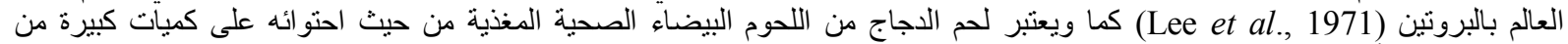

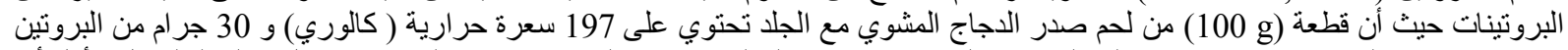

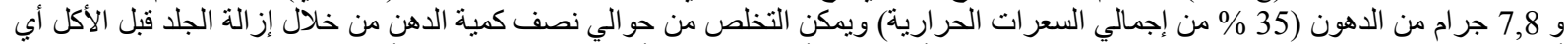

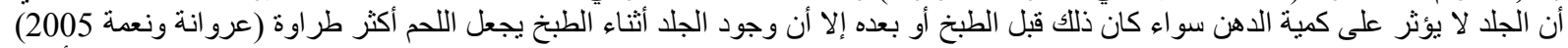

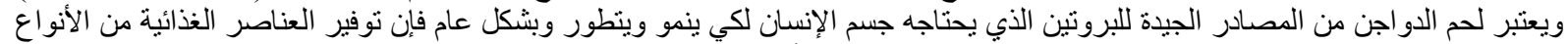

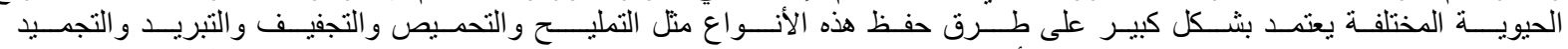
(Cui and Wootton,1988; Love,1980)

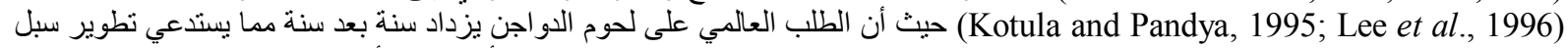

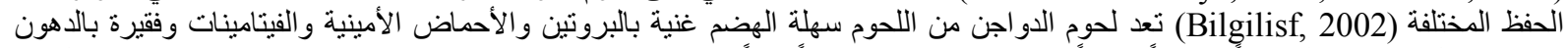

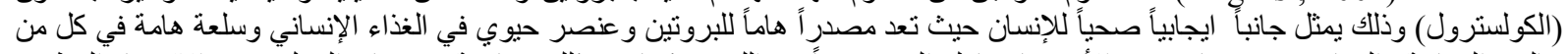

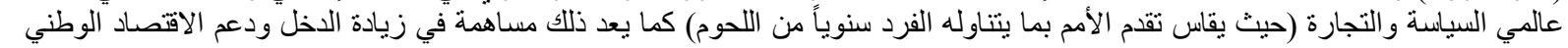
(Ashgar et al., 1990; Sotelo and Perez, 2003)

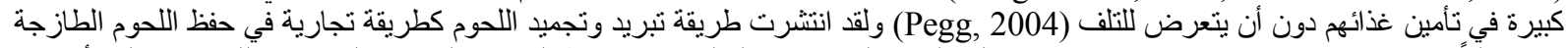

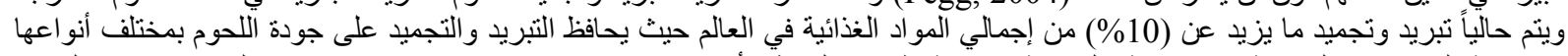

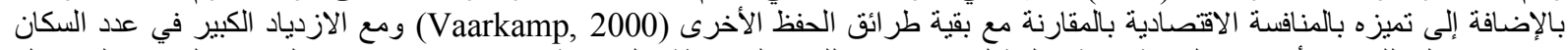

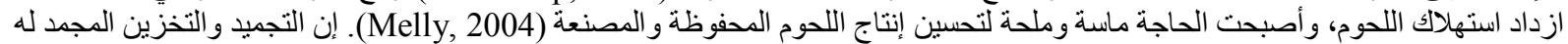

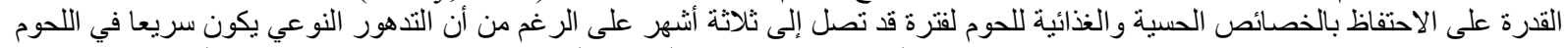
و إن قيمة الـ PHarris and Tall,1994; Erickson,1997)

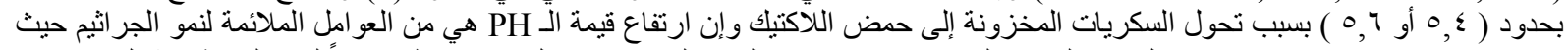

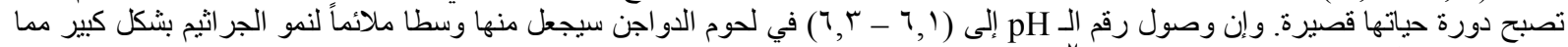

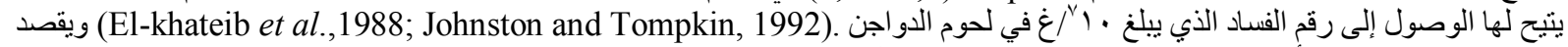

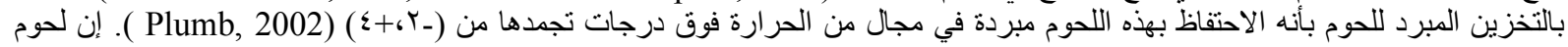

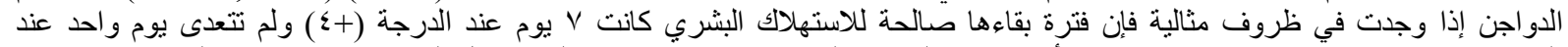

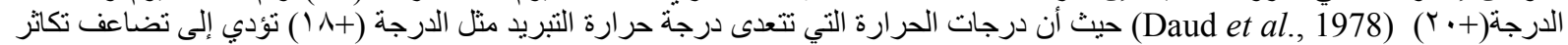

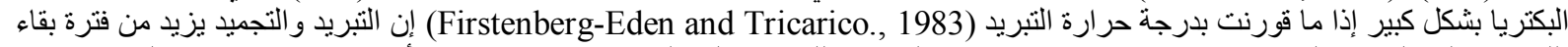

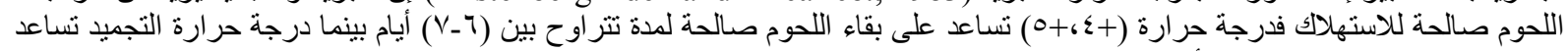

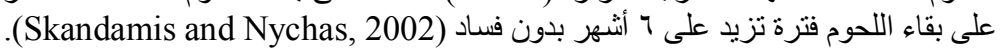

أهداف الدراسة : Objectives

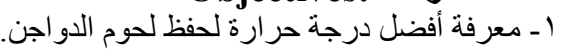

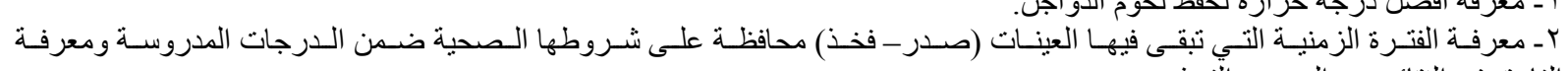

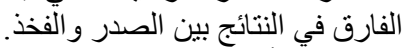

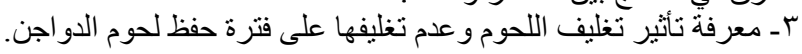

\section{مواد وطر ائق البحث}

\section{MATERIALS and METHODS}

مواد الاختبار:Materials

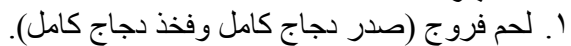

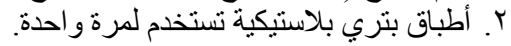

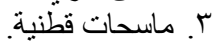

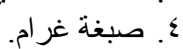
0. أنابيب زجاجية.

Timedia / Nutrient Agar. آغار دم + آغار مغذي + ماءية بيتون + شوربة مغذية

$$
\begin{aligned}
& \text { V. Vحول طبي. } \\
& \text { ^. ورق اكور القصدير. } \\
& \text { 9. أكياس ستوف ماخر. } \\
& \text {. } 1 \text {. كفوف طبية. } \\
& \text { 11 ا. ماصنات مدرجة. } \\
& \text { r I ا. قطن طبي. } \\
& \text { ז } 1 \text { ا. أكياس نايلون. }
\end{aligned}
$$

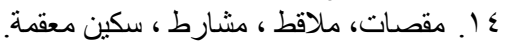

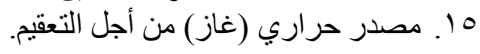

الأجهزة المستخدمة:Instruments

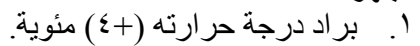

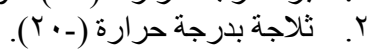

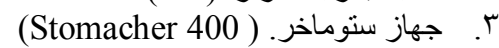




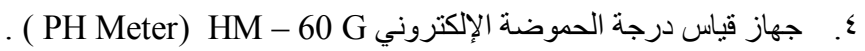

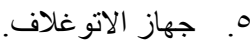

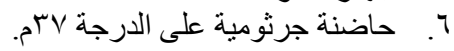

العينـات:

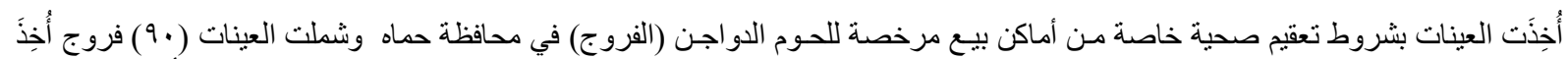

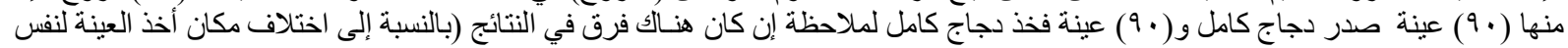

الفروج).

ثم تم وضع العينات في أكياس نايلون صحية ونظيفة ونقلت في حاويات خاصة مبردة إلى مكان الاختبار ومن ثم تم تقسيم العينات بشكل معقم

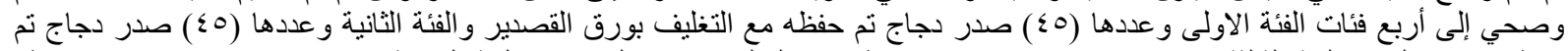

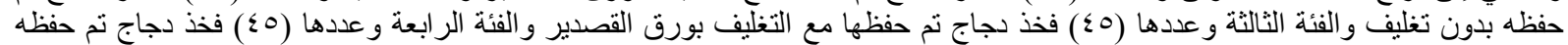

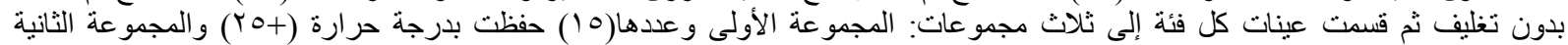

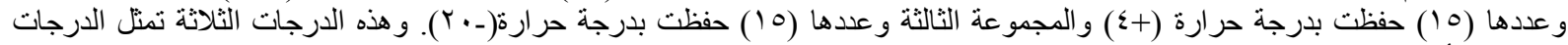

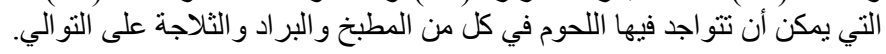

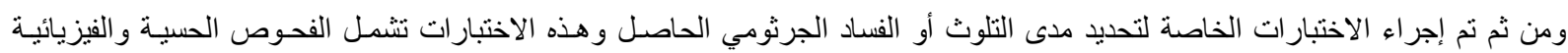

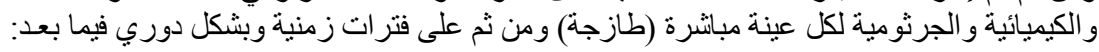

ا ـ الفحص الحسي : ويثمل المظهر العام واللون.

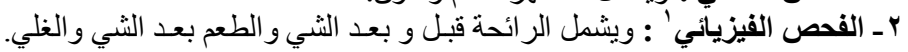

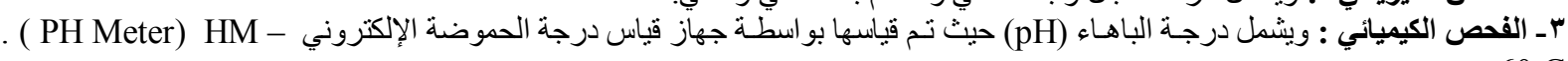
$60 \mathrm{G}$ ع - الفحص الجرثومي: ويشمل التعداد العام للجر اثثم في عينات اللحم ويوضح الجدول التول رقم (1) (1) الأسس المعتمدة لتقدير صلاحية أو فساد اللحوم

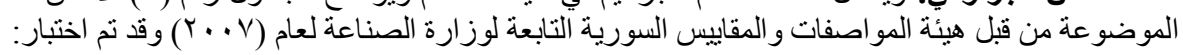

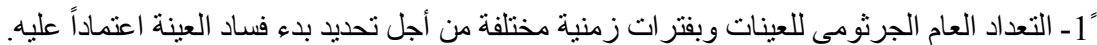

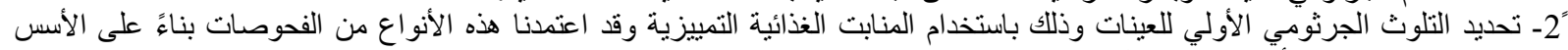

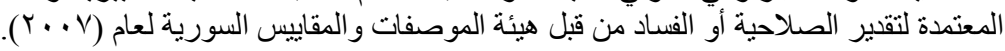
جدول رقم (1): يبين التعداد العام للجر اثيم في اللحوم الصالحة و اللحوم الفاسدة اللحم فاسد

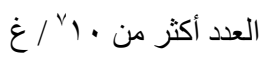

اللحم مسموح به (صالح) العدد أقل من • إم/

ولقد تم القيام بالتعداد العام للجر اثيم حسب الآتي :

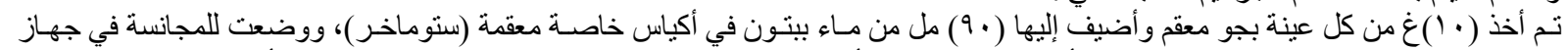

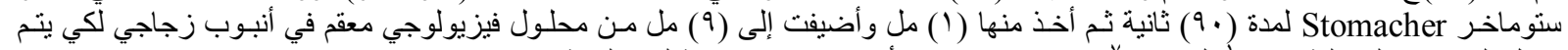

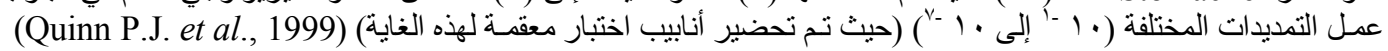

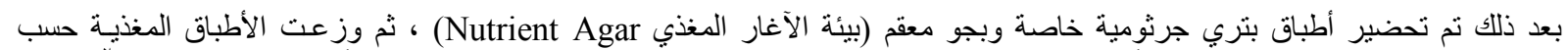

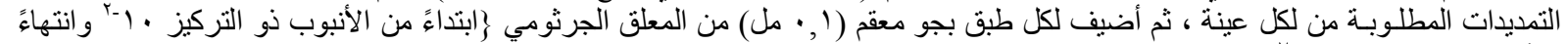

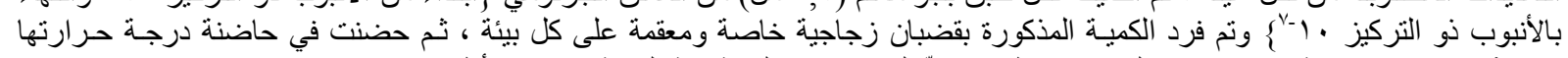

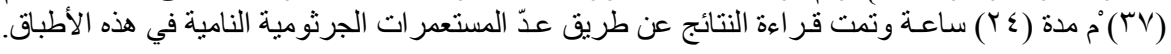

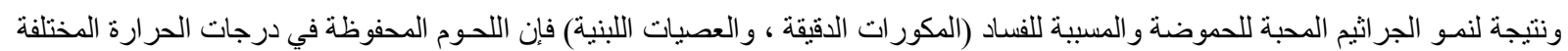

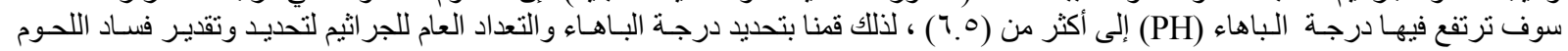
.(Leistner, 1991; Wirth et al., 1990; Sinell, 1986 )

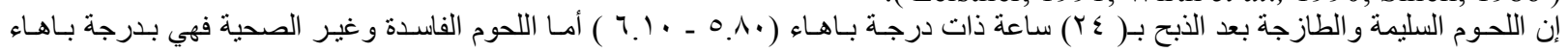

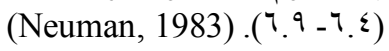

إن هيئة المو اصفات و المقاييس السورية التابعة لوز ارة الصناعة قد حددت عام (V . . r) نقطة (درجة) فساد اللحوم ومنتجاتها وذلك بالإعنماد على:

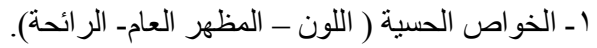

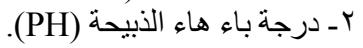

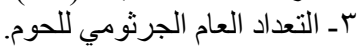

1 : : تم الفحص من قبل مجموعة من الأطباء البيطريين ذوي الكفاءة والمعرفة في كلية الطب البيطري في حماه . 


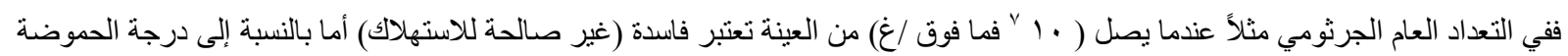

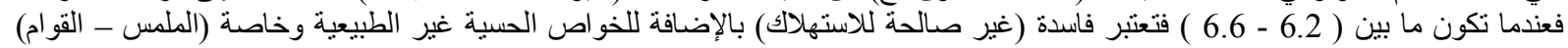
و الر ائحة غير الطبيعية والتي تجعل اللحوم فاسدة.

\section{RESULTS \\ النتأتسـج}

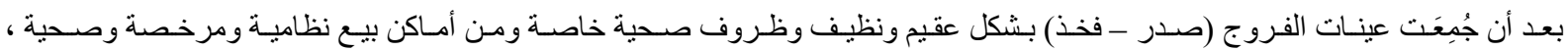

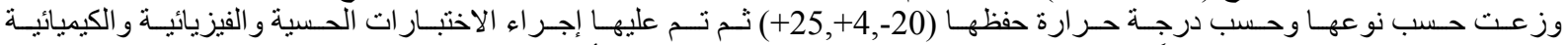

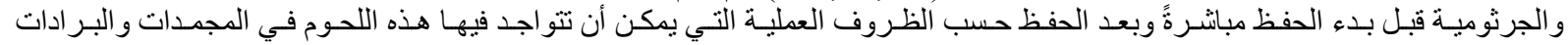

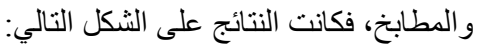

أولاً: العينات قبل الحفظ (طازجة):

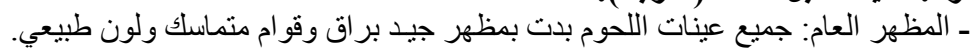

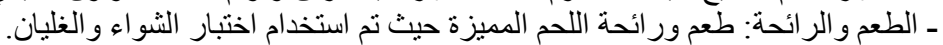

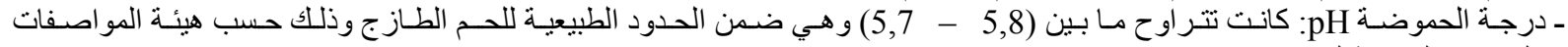

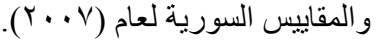

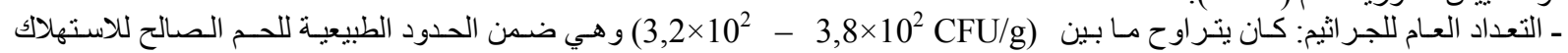

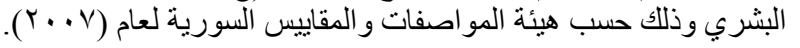

ثم تم على العينات (الصدر و الفخذ) تطبيق الفحص الجرثومي لمعرفة التلوث الأولي للعينـات وذلك باستخدام المنابت الجرثوميـة المغذيـة التمبيزيـة حيث لوحظ:

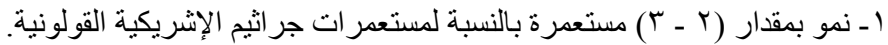

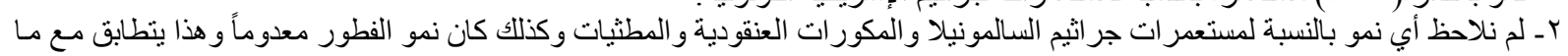

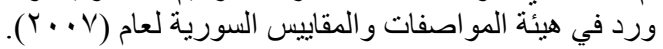

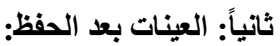

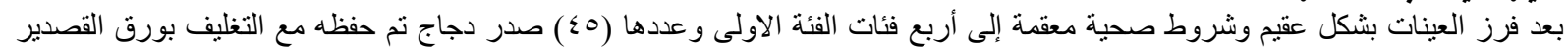

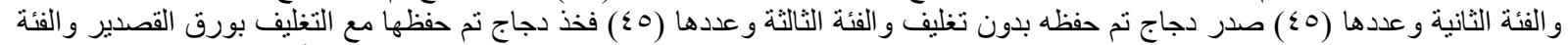

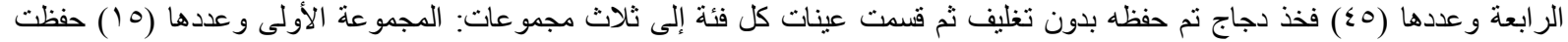

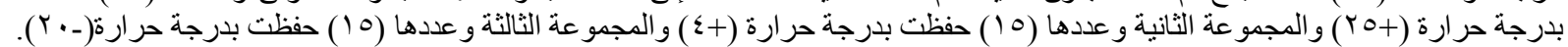

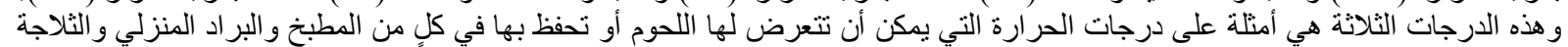

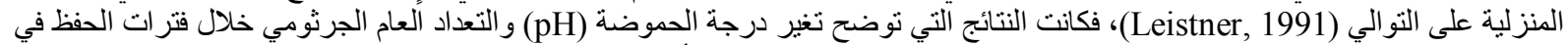

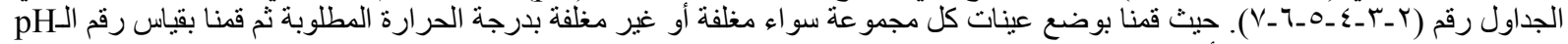

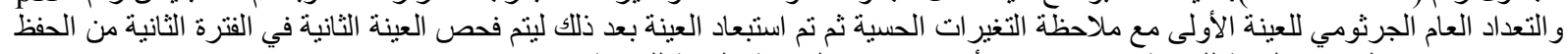

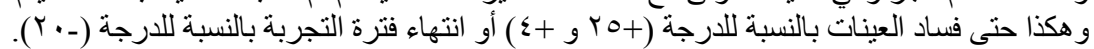

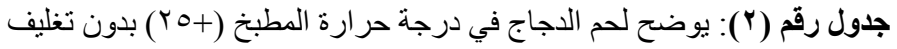

\begin{tabular}{|c|c|c|c|c|c|c|}
\hline \multicolumn{2}{|c|}{ التعداد العام الجرثومي } & \multicolumn{2}{|c|}{ pH } & \multicolumn{2}{|c|}{ المظهر العام والرائحة } & \multirow{2}{*}{$\overline{3} \frac{3}{3}$} \\
\hline فخذ & صدر & فذذ & صدر & فذذ & صدر & \\
\hline $3,5 \times 10^{2} \mathrm{CFU} / \mathrm{g}$ & $3,3 \times 10^{2} \mathrm{CFU} / \mathrm{g}$ & 5,728 & 5,721 & للحن والمميزة. طبيعي ور ائحسة & اللحم المميزة. طبيعي ور ائحسة & 1 \\
\hline $4,9 \times 10^{2} \mathrm{CFU} / \mathrm{g}$ & $3,7 \times 10^{2} \mathrm{CFU} / \mathrm{g}$ & 5,768 & 5,745 & لورنائحة طصيعية. وملمس جـاف & لورائحة طحيعزية. وملمس جـاف & 6 \\
\hline $5,2 \times 10^{3} \mathrm{CFU} / \mathrm{g}$ & $3,4 \times 10^{3} \mathrm{CFU} / \mathrm{g}$ & 5,937 & 5,812 & لورن مصنحة حمضية مقبولة جساف & 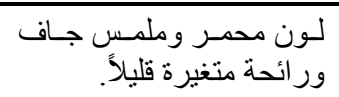 & 12 \\
\hline $2,5 \times 10^{5} \mathrm{CFU} / \mathrm{g}$ & $3,3 \times 10^{4} \mathrm{CFU} / \mathrm{g}$ & 6,125 & 6,023 & 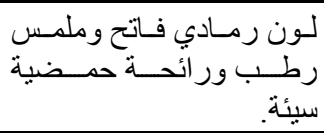 & 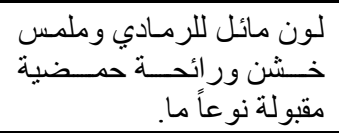 & 18 \\
\hline $\begin{array}{c}5,9 \times 10^{6} \mathrm{CFU} / \mathrm{g} \\
\text { ( بدء الفساد }\end{array}$ & $2,2 \times 10^{5} \mathrm{CFU} / \mathrm{g}$ & 6,382 & 6,295 & مقزز ملمس رخو ورب وسو ائل كريهة رغوية & 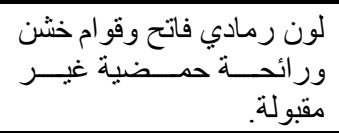 & 24 \\
\hline - & $\begin{array}{r}3,7 \times 10^{6} \text { CFU/g } \\
\text { ( بدء الفساد ) }\end{array}$ & - & 6,365 & - & مقز مقوام رخو ور وسئحسة كريهـة رغوية & 36 \\
\hline
\end{tabular}


$\underline{\text { Assiut Vet. Med. J. Vol. } 60 \text { No. } 140 \text { January } 2014}$

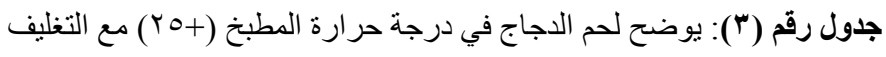

\begin{tabular}{|c|c|c|c|c|c|}
\hline \multicolumn{2}{|c|}{ التعداد العام الجرثومي } & \multicolumn{2}{|c|}{ pH } & المظهر العام والرائحة & $\begin{array}{c}\overline{7} \\
: 0 \\
7\end{array}$ \\
\hline فخذ & صدر & فخذ & صدر & صدر & : \\
\hline $3,8 \times 10^{2} \mathrm{CFU} / \mathrm{g}$ & $3,3 \times 10^{2} \mathrm{CFU} / \mathrm{g}$ & 5,838 & 5,731 & 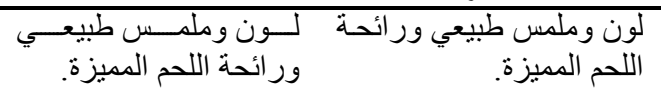 & 1 \\
\hline $8,7 \times 10^{3} \mathrm{CFU} / \mathrm{g}$ & $6,5 \times 10^{3} \mathrm{CFU} / \mathrm{g}$ & 5,892 & 5,782 & 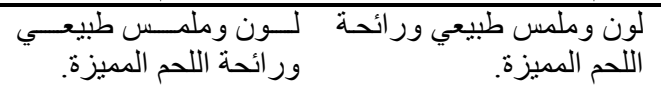 & 6 \\
\hline $7,9 \times 10^{4} \mathrm{CFU} / \mathrm{g}$ & $1,7 \times 10^{4} \mathrm{CFU} / \mathrm{g}$ & 6,058 & 5,863 & 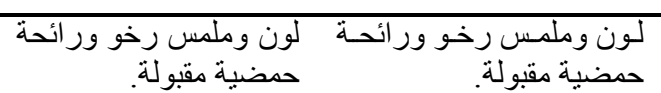 & 12 \\
\hline $1,3 \times 10^{6} \mathrm{CFU} / \mathrm{g}$ & $2,4 \times 10^{5} \mathrm{CFU} / \mathrm{g}$ & 6,253 & 6,184 & 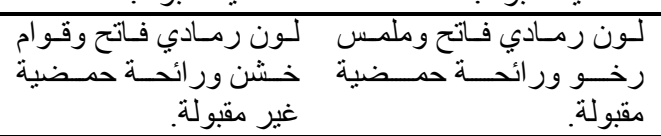 & 18 \\
\hline $\begin{array}{c}5,3 \times 10^{8} \mathrm{CFU} / \mathrm{g} \\
\text { (فاسد) }\end{array}$ & $1,5 \times 10^{6} \mathrm{CFU} / \mathrm{g}$ & 6,428 & 6,302 & 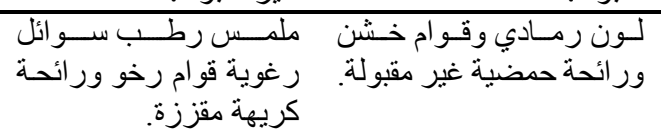 & 24 \\
\hline - & $\begin{array}{l}3,2 \times 10^{8} \mathrm{CFU} / \mathrm{g} \\
\text { (فاسد) }\end{array}$ & . & 6,413 & 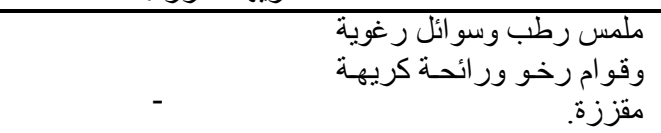 & 36 \\
\hline
\end{tabular}

جدول رقم (؛) : يوضح لحم الدجاج المخزن على الدرجة (+ء) بدون تغليف

\begin{tabular}{|c|c|c|c|c|c|c|}
\hline \multicolumn{2}{|c|}{ التعداد العام الجرثومي } & \multicolumn{2}{|c|}{ pH } & \multicolumn{2}{|c|}{ المظهر العام والرائحة } & \multirow{2}{*}{$\overline{\frac{7}{3}} \frac{3}{3}$} \\
\hline فخذ & صدر & فذذ & صدر & فخذ & صدر & \\
\hline $3,3 \times 10^{2} \mathrm{CFU} / \mathrm{g}$ & $3,2 \times 10^{2} \mathrm{CFU} / \mathrm{g}$ & $\begin{array}{c}5,74 \\
1\end{array}$ & 5,736 & 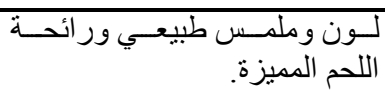 & 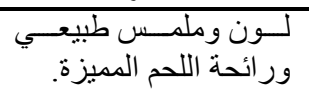 & 1 \\
\hline $3,5 \times 10^{2} \mathrm{CFU} / \mathrm{g}$ & $3,4 \times 10^{2} \mathrm{CFU} / \mathrm{g}$ & 5,748 & 5,742 & 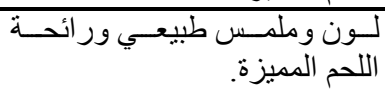 & ور لــونة وملمــس اللحم المميزة. & 6 \\
\hline $3,4 \times 10^{3} \mathrm{CFU} / \mathrm{g}$ & $2,3 \times 10^{3} \mathrm{CFU} / \mathrm{g}$ & 5,815 & 5,803 & 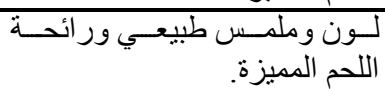 & 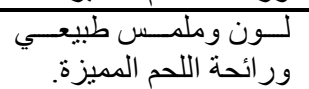 & 12 \\
\hline $4,6 \times 10^{3} \mathrm{CFU} / \mathrm{g}$ & $3,5 \times 10^{3} \mathrm{CFU} / \mathrm{g}$ & 5,875 & 5,861 & 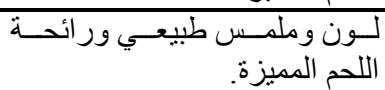 & 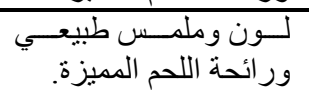 & 18 \\
\hline $5,8 \times 10^{3} \mathrm{CFU} / \mathrm{g}$ & $4,6 \times 10^{3} \mathrm{CFU} / \mathrm{g}$ & 5,912 & 5,902 & 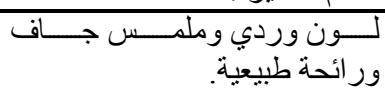 & جاف ور ائحةِ طبي وملية. & 24 \\
\hline $2,4 \times 10^{4} \mathrm{CFU} / \mathrm{g}$ & $2,2 \times 10^{4} \mathrm{CFU} / \mathrm{g}$ & 5,956 & 5,937 & 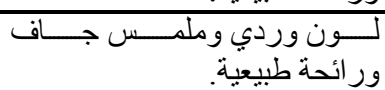 & جاف ور ائحةِ طبيعية. وملمـسـس & 36 \\
\hline $4,5 \times 10^{4} \mathrm{CFU} / \mathrm{g}$ & $3,3 \times 10^{4} \mathrm{CFU} / \mathrm{g}$ & 6,025 & 6,004 & 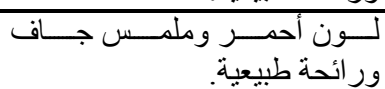 & 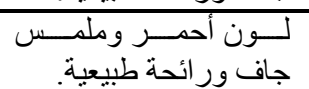 & 48 \\
\hline $5,6 \times 10^{4} \mathrm{CFU} / \mathrm{g}$ & $4,4 \times 10^{4} \mathrm{CFU} / \mathrm{g}$ & 6,117 & 6,092 & 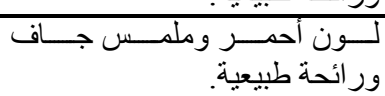 & 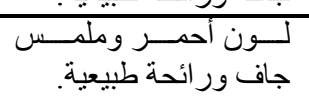 & 72 \\
\hline $1,3 \times 10^{5} \mathrm{CFU} / \mathrm{g}$ & $5,6 \times 10^{4} \mathrm{CFU} / \mathrm{g}$ & 6,200 & 6,155 & 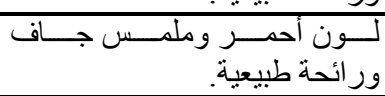 & 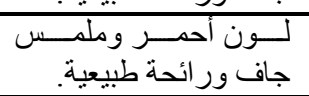 & 96 \\
\hline $3,7 \times 10^{5} \mathrm{CFU} / \mathrm{g}$ & $1,4 \times 10^{5} \mathrm{CFU} / \mathrm{g}$ & 6,286 & 6,227 & 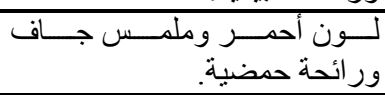 & ور لـون أحمة حمضرملمسة. جـاف & 120 \\
\hline $2,3 \times 10^{6} \mathrm{CFU} / \mathrm{g}$ & $3,9 \times 10^{5} \mathrm{CFU} / \mathrm{g}$ & 6,367 & 6,311 & 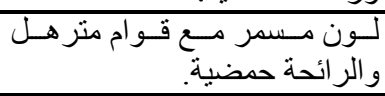 & 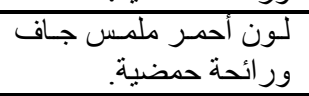 & 144 \\
\hline $\begin{array}{c}5,4 \times 10^{7} \mathrm{CFU} / \mathrm{g} \\
\text { (فاسد ) }\end{array}$ & $3,4 \times 10^{6} \mathrm{CFU} / \mathrm{g}$ & 6,425 & 6,384 & 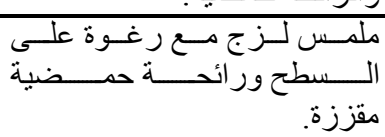 & 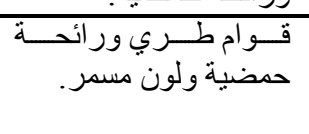 & 168 \\
\hline- & $\begin{array}{c}4,3 \times 10^{7} \mathrm{CFU} / \mathrm{g} \\
\text { (فاسد ) }\end{array}$ & - & 6,442 & - & 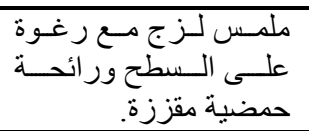 & 192 \\
\hline
\end{tabular}


جدول رقم (•): يوضح لحم الاجاج المخزن على الدرجة (+乏) مع التغليف

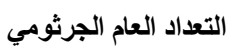

pH

المظهر العام والرائحة

\begin{tabular}{|c|c|c|c|c|c|c|}
\hline فخذ & صدر & فخذ & صدر & فذذ & صدر & \\
\hline $3,3 \times 10^{2} \mathrm{CFU} / \mathrm{g}$ & $3,2 \times 10^{2} \mathrm{CFU} / \mathrm{g}$ & 5,749 & 5,742 & 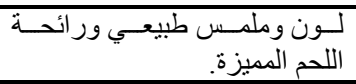 & 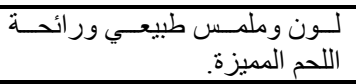 & 1 \\
\hline $7,7 \times 10^{2} \mathrm{CFU} / \mathrm{g}$ & $6,5 \times 10^{2} \mathrm{CFU} / \mathrm{g}$ & 5,758 & 5,751 & اللــــن المميزة. & للـــــ المميزة. & 6 \\
\hline $5,4 \times 10^{3} \mathrm{CFU} / \mathrm{g}$ & $2,4 \times 10^{3} \mathrm{CFU} / \mathrm{g}$ & 5,825 & 5,812 & اللـــم المميزة. & اللــم المميزة. & 12 \\
\hline $7,8 \times 10^{3} \mathrm{CFU} / \mathrm{g}$ & $6,6 \times 10^{3} \mathrm{CFU} / \mathrm{g}$ & 5,891 & 5,873 & 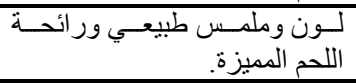 & 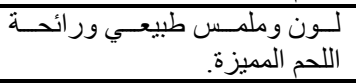 & 18 \\
\hline $9,7 \times 10^{3} \mathrm{CFU} / \mathrm{g}$ & $7,7 \times 10^{3} \mathrm{CFU} / \mathrm{g}$ & 5,931 & 5,913 & اللــــن المميزة. & لـــــ المميزة. & 24 \\
\hline $7,5 \times 10^{4} \mathrm{CFU} / \mathrm{g}$ & $6,3 \times 10^{4} \mathrm{CFU} / \mathrm{g}$ & 5,975 & 5,958 & اللـــون المميزة. & 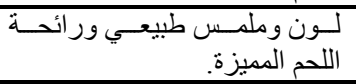 & 36 \\
\hline $8,7 \times 10^{4} \mathrm{CFU} / \mathrm{g}$ & $7,5 \times 10^{4} \mathrm{CFU} / \mathrm{g}$ & 6,041 & 6,025 & 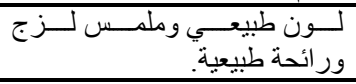 & 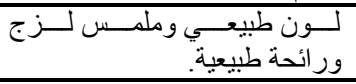 & 48 \\
\hline $9,9 \times 10^{4} \mathrm{CFU} / \mathrm{g}$ & $8,7 \times 10^{4} \mathrm{CFU} / \mathrm{g}$ & 6,125 & 6,100 & 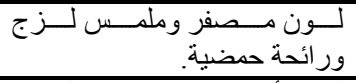 & 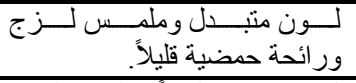 & 72 \\
\hline $7,5 \times 10^{5} \mathrm{CFU} / \mathrm{g}$ & $5,3 \times 10^{5} \mathrm{CFU} / \mathrm{g}$ & 6,207 & 6,178 & 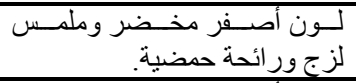 & 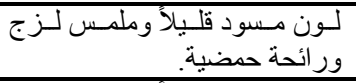 & 96 \\
\hline $8,6 \times 10^{6} \mathrm{CFU} / \mathrm{g}$ & $7,8 \times 10^{5} \mathrm{CFU} / \mathrm{g}$ & 6,312 & 6,246 & 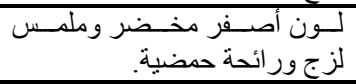 & 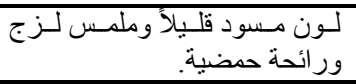 & 120 \\
\hline $\begin{array}{c}9,8 \times 10^{7} \mathrm{CFU} / \mathrm{g} \\
\text { (فاسد) }\end{array}$ & $6,4 \times 10^{6} \mathrm{CFU} / \mathrm{g}$ & 6,436 & 6,325 & 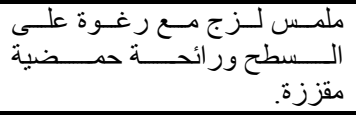 & 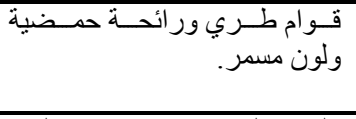 & 144 \\
\hline- & $\begin{array}{c}7,7 \times 10^{7} \text { CFU/g } \\
\text { (فاسد) }\end{array}$ & - & 6,458 & - & 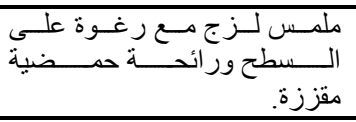 & 168 \\
\hline
\end{tabular}

جدول رقم (צ): يوضح لحم الدجاج المخزن على الدرجة (-- †) بدون تغليف

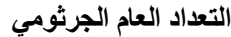

PH

المظهز العام والرائحة

高零

\begin{tabular}{|c|c|c|c|c|c|c|}
\hline فخذ & صدر & فخذ & صدر & فذذَ & صدر & \\
\hline $3,3 \times 10^{2} \mathrm{CFU} / \mathrm{g}$ & $3,2 \times 10^{2} \mathrm{CFU} / \mathrm{g}$ & 5,741 & 5,722 & 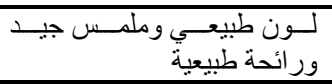 & 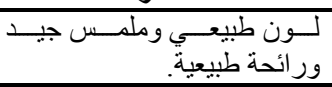 & 1 \\
\hline $4,7 \times 10^{2} \mathrm{CFU} / \mathrm{g}$ & $4,3 \times 10^{2} \mathrm{CFU} / \mathrm{g}$ & 5,784 & 5,757 & ور لـون طبيعة طبيعية وملمس جـساف & ور لـون طبيعة طبيعيةي وملمسلس جـاف & 15 \\
\hline $7,8 \times 10^{2} \mathrm{CFU} / \mathrm{g}$ & $5,7 \times 10^{2} \mathrm{CFU} / \mathrm{g}$ & 5,828 & 5,792 & 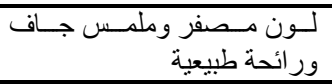 & ور لـون طبيعة طبيعية وملهـس جــاف & 30 \\
\hline $2,4 \times 10^{3} \mathrm{CFU} / \mathrm{g}$ & $8,2 \times 10^{2} \mathrm{CFU} / \mathrm{g}$ & 5,868 & 5,825 & 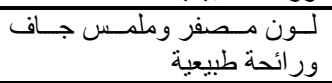 & 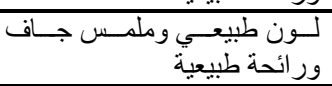 & 45 \\
\hline $3,7 \times 10^{3} \mathrm{CFU} / \mathrm{g}$ & $2,2 \times 10^{3} \mathrm{CFU} / \mathrm{g}$ & 5,911 & 5,861 & 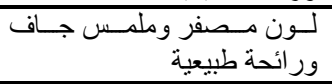 & 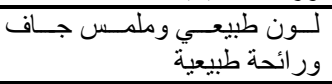 & 60 \\
\hline $4,9 \times 10^{3} \mathrm{CFU} / \mathrm{g}$ & $3,6 \times 10^{3} \mathrm{CFU} / \mathrm{g}$ & 5,952 & 5,896 & 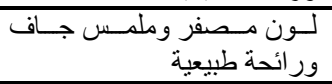 & 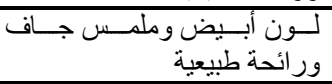 & 75 \\
\hline $1,3 \times 10^{4} \mathrm{CFU} / \mathrm{g}$ & $5,1 \times 10^{3} \mathrm{CFU} / \mathrm{g}$ & 5,996 & 5,926 & 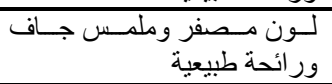 & 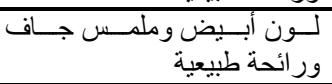 & 90 \\
\hline $3,5 \times 10^{4} \mathrm{CFU} / \mathrm{g}$ & $2,2 \times 10^{4} \mathrm{CFU} / \mathrm{g}$ & 6,037 & 5,964 & 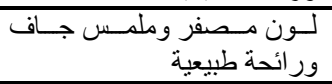 & 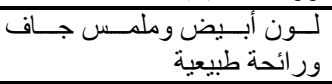 & 105 \\
\hline $4,7 \times 10^{4} \mathrm{CFU} / \mathrm{g}$ & $4,1 \times 10^{4} \mathrm{CFU} / \mathrm{g}$ & 6,081 & 6,000 & 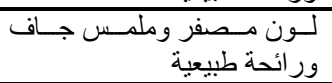 & 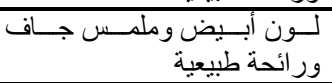 & 120 \\
\hline $6,5 \times 10^{4} \mathrm{CFU} / \mathrm{g}$ & $5,4 \times 10^{4} \mathrm{CFU} / \mathrm{g}$ & 6,124 & 6,035 & 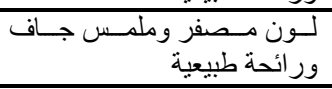 & 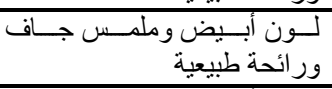 & 135 \\
\hline $1,1 \times 10^{5} \mathrm{CFU} / \mathrm{g}$ & $5,7 \times 10^{4} \mathrm{CFU} / \mathrm{g}$ & 6,167 & 6,071 & 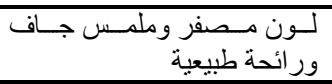 & 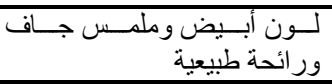 & 150 \\
\hline $3,4 \times 10^{5} \mathrm{CFU} / \mathrm{g}$ & $2,3 \times 10^{5} \mathrm{CFU} / \mathrm{g}$ & 6,199 & 6,096 & ور لـونحة طـيعية وملكسس جــاف & 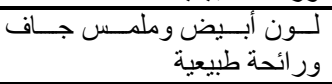 & 165 \\
\hline $5,5 \times 10^{5} \mathrm{CFU} / \mathrm{g}$ & $3,4 \times 10^{5} \mathrm{CFU} / \mathrm{g}$ & 6,214 & 6,113 & 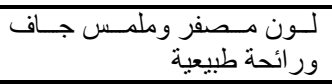 & 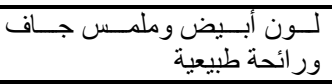 & 180 \\
\hline
\end{tabular}


جدول رقم (V): يوضح لحم الدجاج المخزن على الدرجة (-• r) مع التغليف

\begin{tabular}{|c|c|c|c|c|c|}
\hline \multicolumn{2}{|c|}{ التعداد العام الجرثومي } & \multicolumn{2}{|c|}{ pH } & المظهر العام والرائحة & \multirow{2}{*}{ 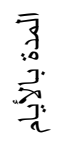 } \\
\hline فخذ & صدر & فخذ & صدر & صدر & \\
\hline $3,4 \times 10^{2} \mathrm{CFU} / \mathrm{g}$ & $3,3 \times 10^{2} \mathrm{CFU} / \mathrm{g}$ & 5,748 & 5,732 & 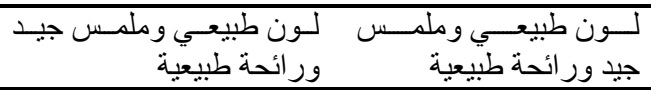 & 1 \\
\hline $4,6 \times 10^{2} \mathrm{CFU} / \mathrm{g}$ & $4,3 \times 10^{2} \mathrm{CFU} / \mathrm{g}$ & 5,780 & 5,756 & 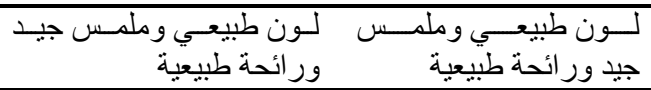 & 15 \\
\hline $5,8 \times 10^{2} \mathrm{CFU} / \mathrm{g}$ & $4,5 \times 10^{2} \mathrm{CFU} / \mathrm{g}$ & 5,810 & 5,780 & 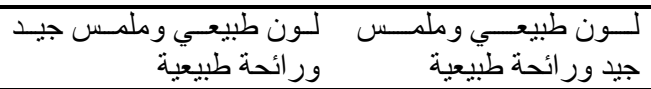 & 30 \\
\hline $9,7 \times 10^{2} \mathrm{CFU} / \mathrm{g}$ & $7,7 \times 10^{2} \mathrm{CFU} / \mathrm{g}$ & 5,843 & 5,807 & 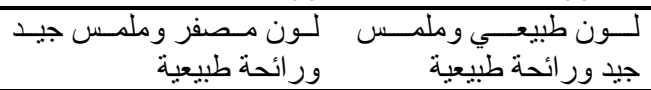 & 45 \\
\hline $2,4 \times 10^{3} \mathrm{CFU} / \mathrm{g}$ & $1,3 \times 10^{3} \mathrm{CFU} / \mathrm{g}$ & 5,875 & 5,830 & 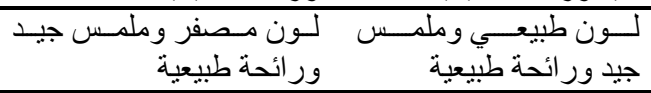 & 60 \\
\hline $3,8 \times 10^{3} \mathrm{CFU} / \mathrm{g}$ & $3,4 \times 10^{3} \mathrm{CFU} / \mathrm{g}$ & 5,906 & 5,852 & 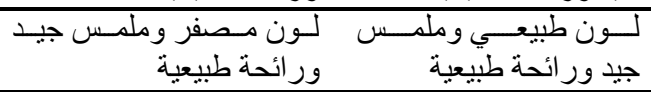 & 75 \\
\hline $5,6 \times 10^{3} \mathrm{CFU} / \mathrm{g}$ & $4,3 \times 10^{3} \mathrm{CFU} / \mathrm{g}$ & 5,938 & 5,875 & 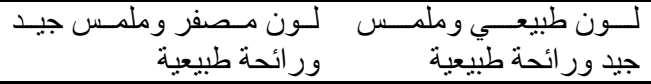 & 90 \\
\hline $7,7 \times 10^{3} \mathrm{CFU} / \mathrm{g}$ & $6,5 \times 10^{3} \mathrm{CFU} / \mathrm{g}$ & 5,969 & 5,899 & 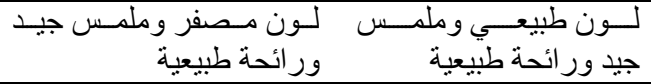 & 105 \\
\hline $8,8 \times 10^{3} \mathrm{CFU} / \mathrm{g}$ & $8,2 \times 10^{3} \mathrm{CFU} / \mathrm{g}$ & 6,002 & 5,923 & 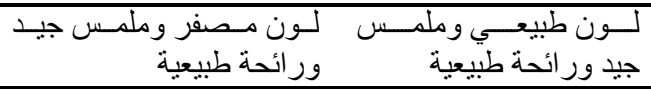 & 120 \\
\hline $4,7 \times 10^{4} \mathrm{CFU} / \mathrm{g}$ & $4,2 \times 10^{4} \mathrm{CFU} / \mathrm{g}$ & 6,034 & 5,948 & 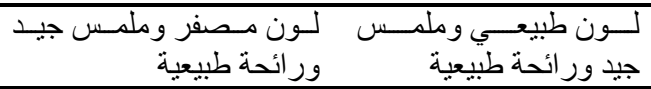 & 135 \\
\hline $6,8 \times 10^{4} \mathrm{CFU} / \mathrm{g}$ & $6,3 \times 10^{4} \mathrm{CFU} / \mathrm{g}$ & 6,068 & 5,972 & 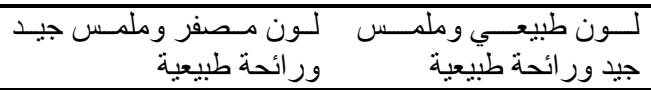 & 150 \\
\hline $1,2 \times 10^{5} \mathrm{CFU} / \mathrm{g}$ & $7,5 \times 10^{4} \mathrm{CFU} / \mathrm{g}$ & 6,090 & 5,990 & 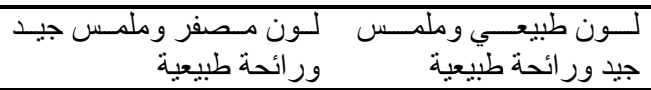 & 165 \\
\hline $3,4 \times 10^{5} \mathrm{CFU} / \mathrm{g}$ & $2,2 \times 10^{5} \mathrm{CFU} / \mathrm{g}$ & 6,108 & 6,004 & 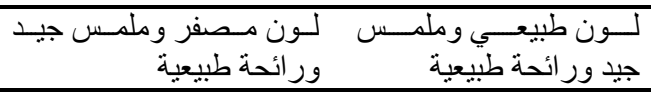 & 180 \\
\hline
\end{tabular}

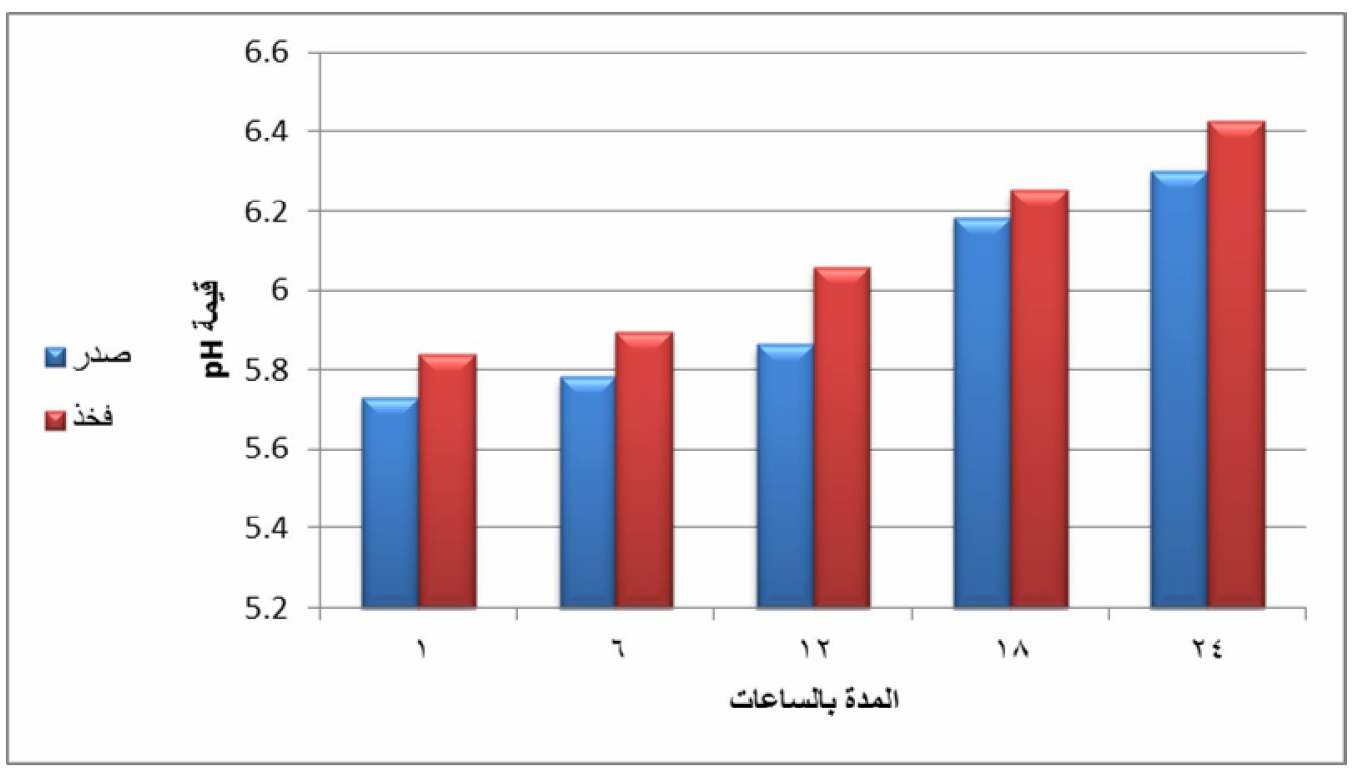

مخطط رقم (1): يوضح تغير pH العينات المغلفة بدرجة حر ارة المطبخ (25+) خلال فترة الاختبار 


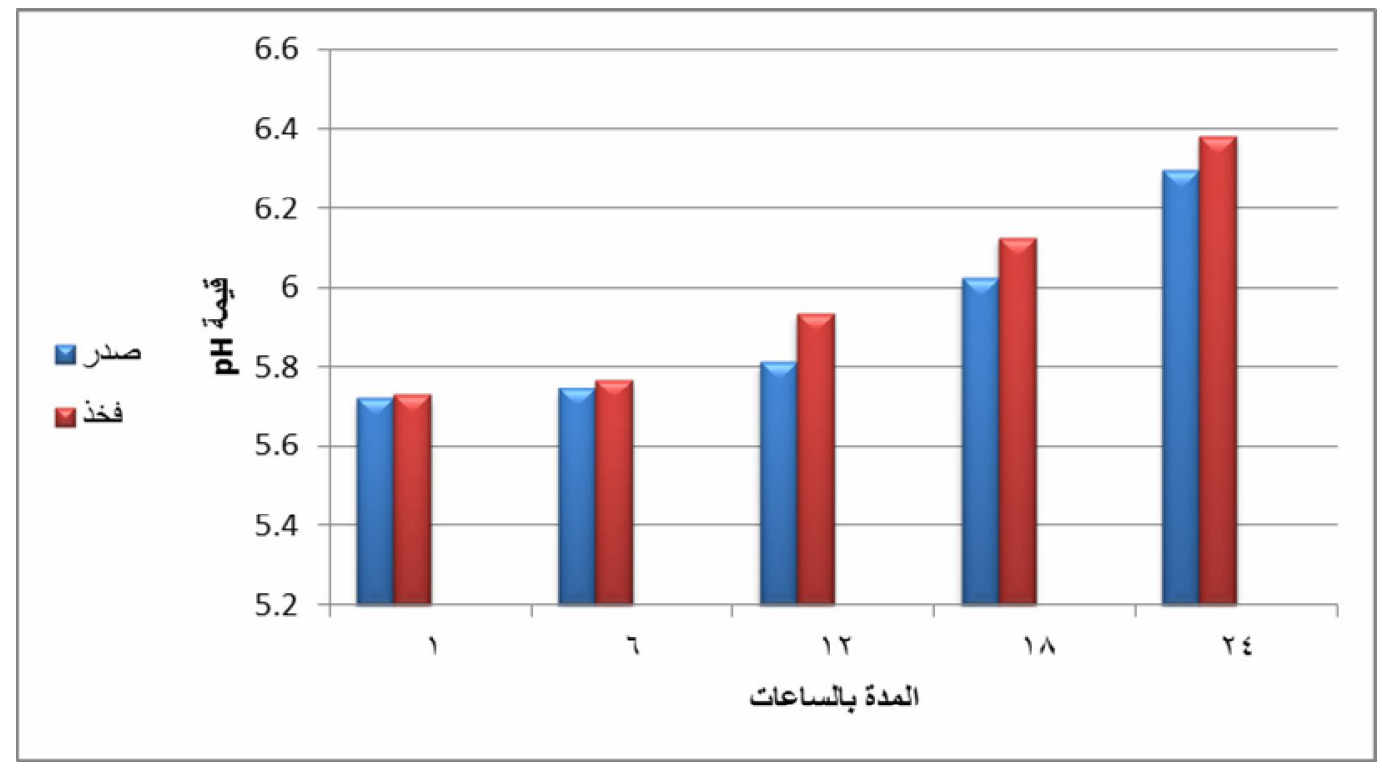

مخطط رقم (؟): يوضح تغير pH العينات الغير مغلفة بدرجة حرارة المطبخ (25+) خلال فترة الاختبار

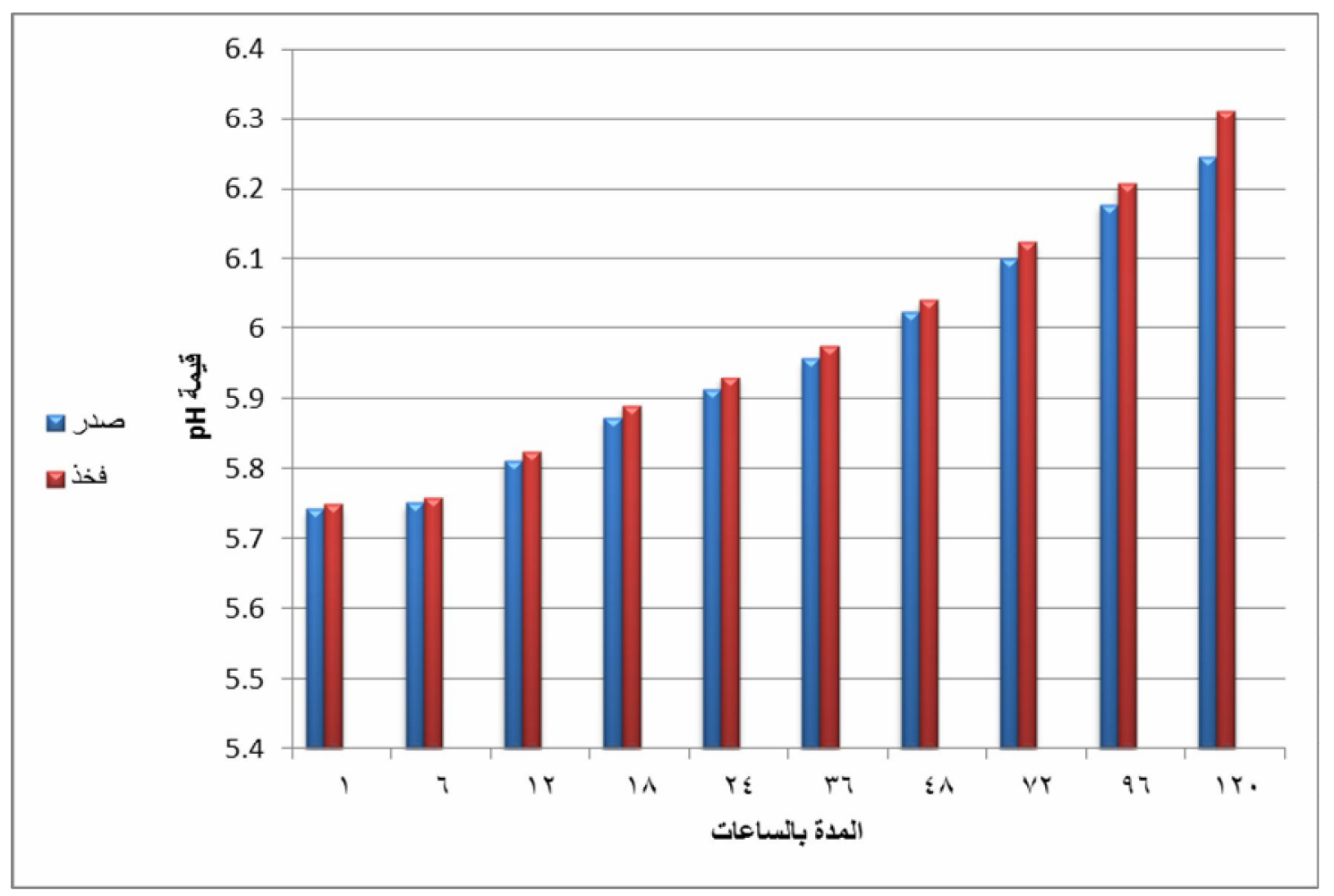

مخطط رقم (ॅ): يوضح تغير pH العينات المغلفة بدرجة حر ارة(4+) خلال فترة الحفظ 


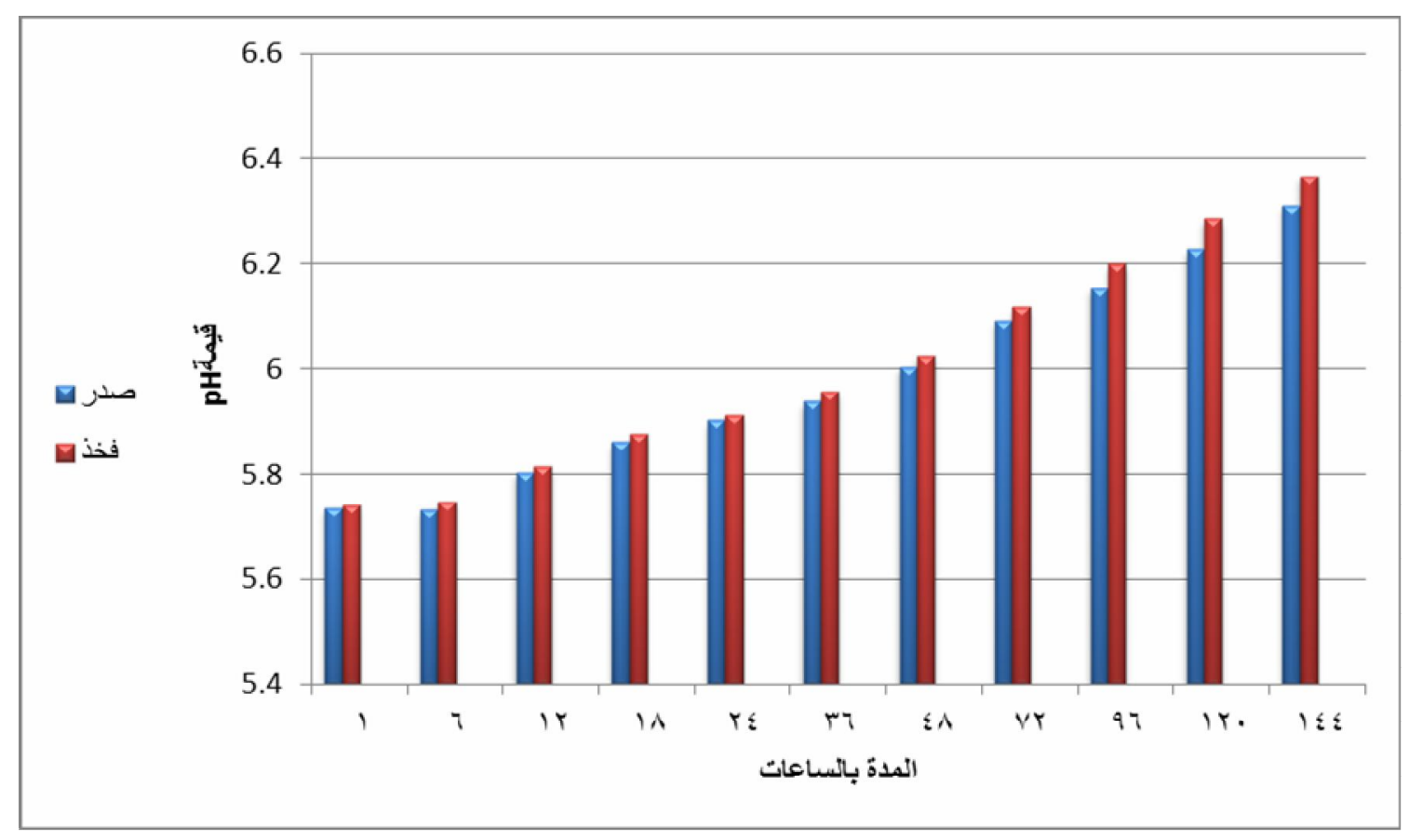

مخطط رقم (؟): يوضح تغير pH العينات الغير مغلفة بدرجة حرارة(4+) خلال فترة الحفظ

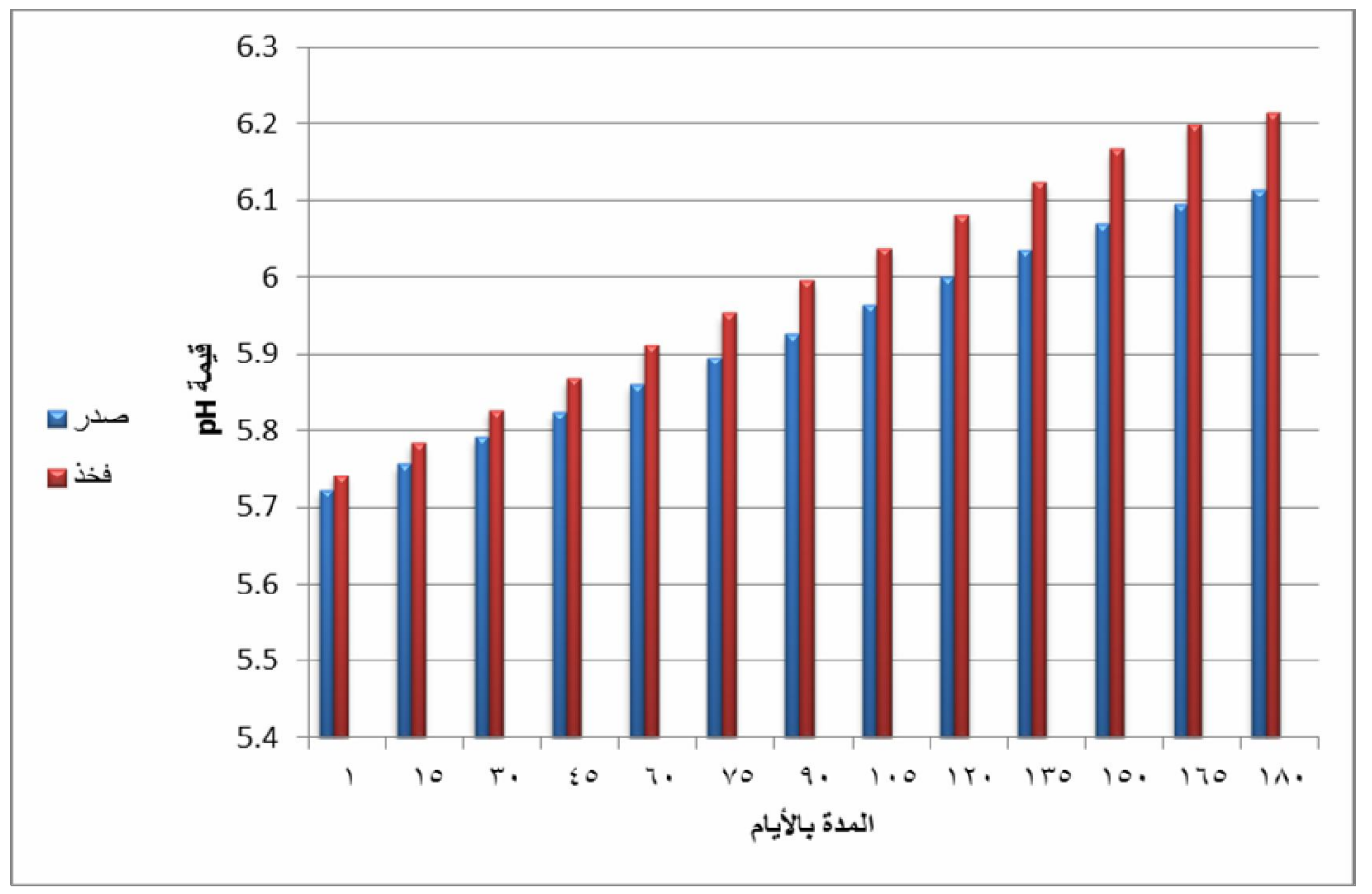

مخطط رقم (0): يوضح تغير pH العينات الغير مغلفة بدرجة حر ارة (-• () خلال فترة الحفظ 


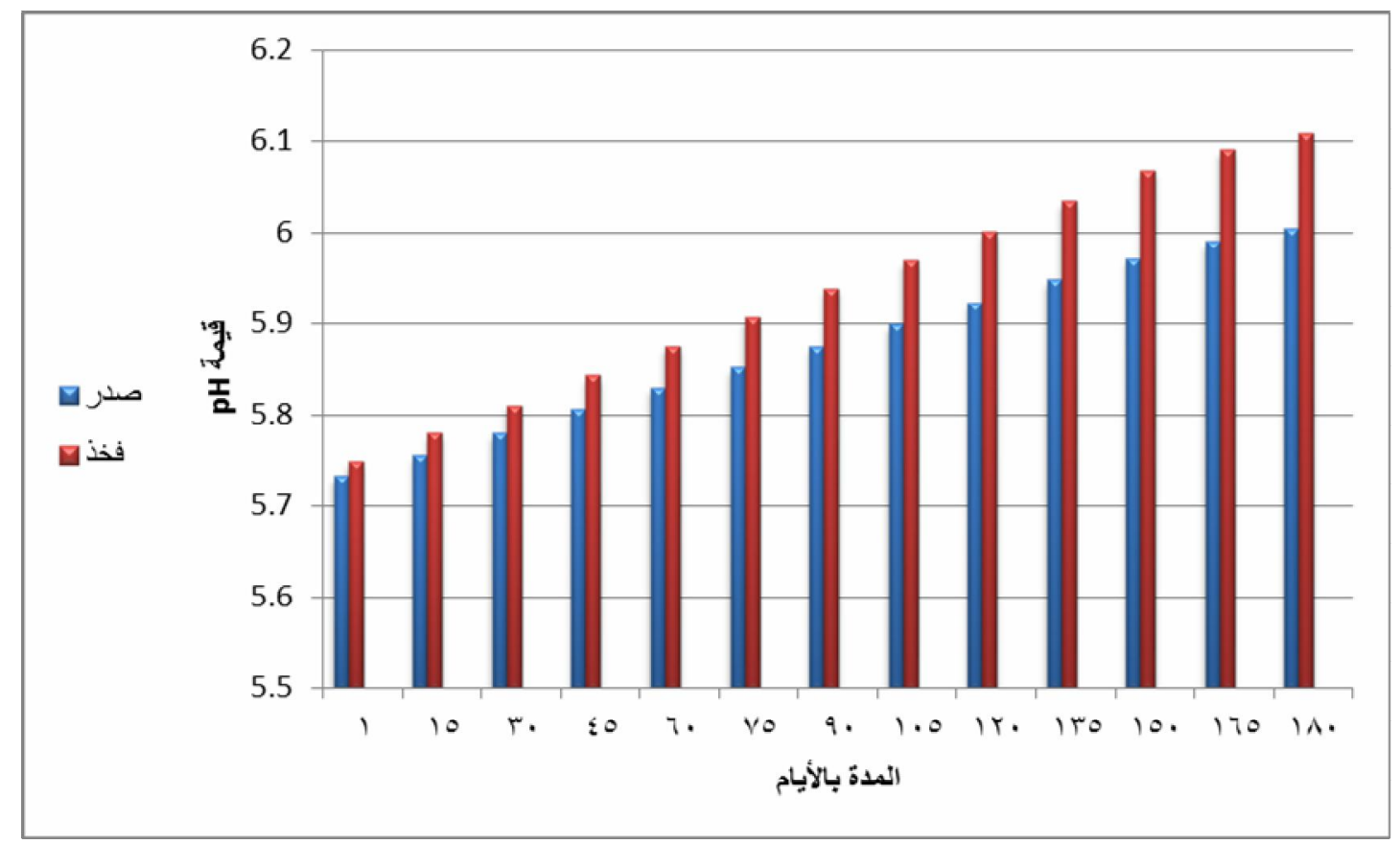

مخطط رقم (ך): يوضح تغير pH العينات المغلفة على درجة حرارة (-• خ) خلال فترة الحفظ

\section{DISCUSSION}

\section{المناقشــة}

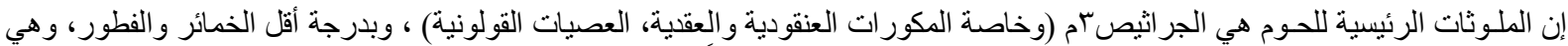

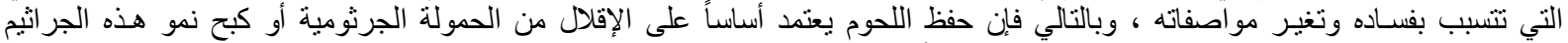

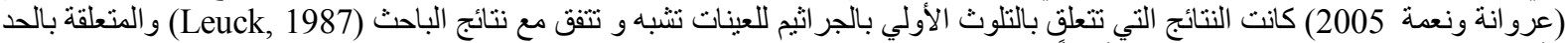

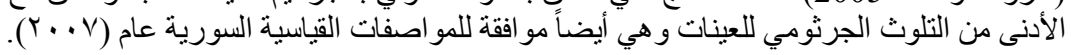

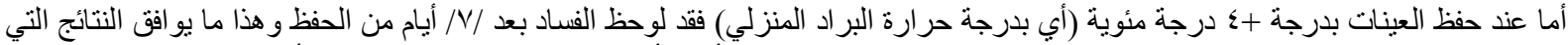

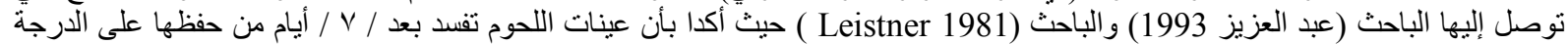

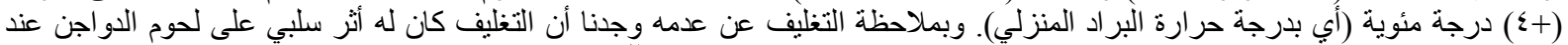

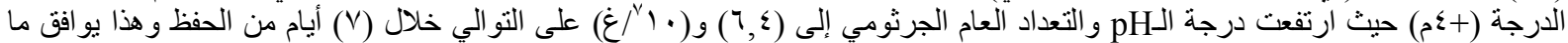

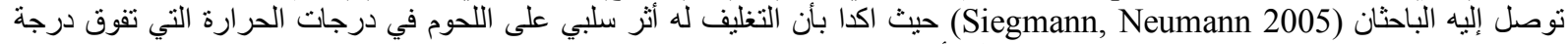

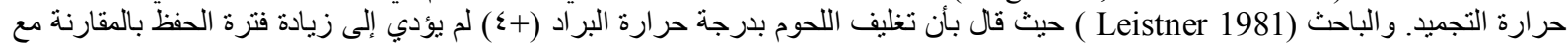
درجة حرارة التجميد.

و عند حفظ العينات على الدرجة +or إم فقد ظهر الفساد بعد / ع/ ساعة من حفظها وهذا يتفق مع ما توصل إليه الباحث (عبد العزيز 1993)

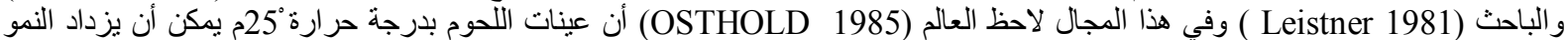

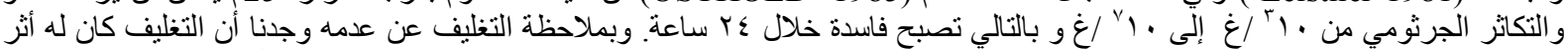

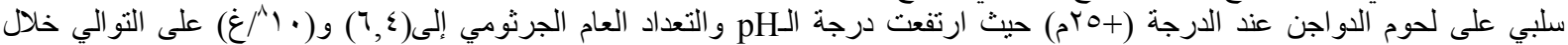

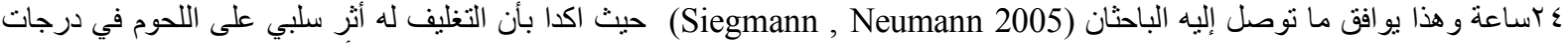

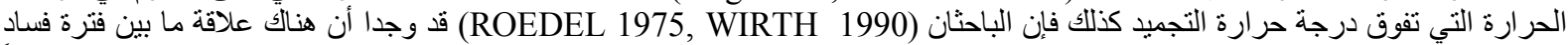

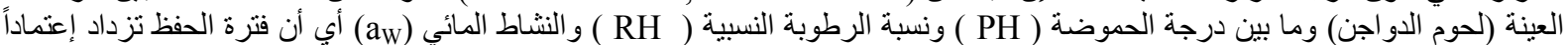

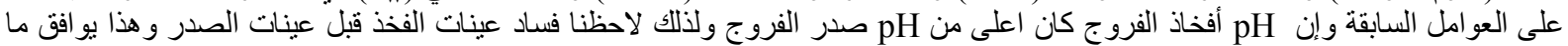
توصل إليه الباحثان السابقان.

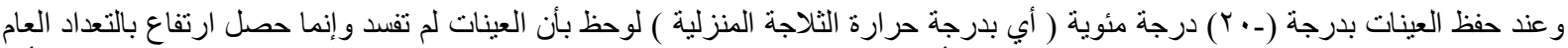

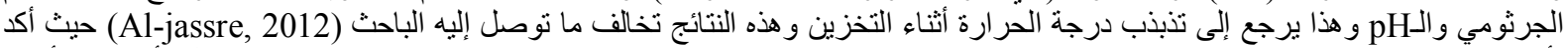

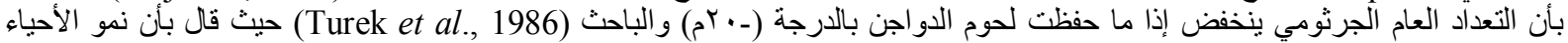
الدقيقة الدسببة للفساد ينخفض بدرجة عظيمة عند الوصول الى درجة حرارة التجميد ( - •rم ) في مخازن التجميد التجارية والمنزلية.

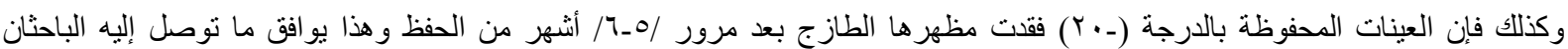
(Harris and Tall, 1994 Erickson, 1997)

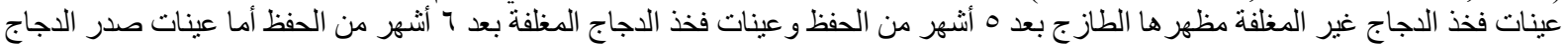
غير المغلفة فقت مظهر ها الطازج بعد 1 أثهر من الحفظو وعينات صدر الدجاج المغلفة بعد > أثشهر من الحفظ. و هذا يو افق ما توصل اليه الباحث 
(Anon, 2001)

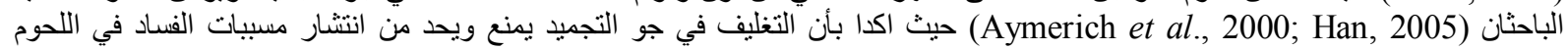
وبالتالي تزداد فترة الحفظ اذا ما خزنت لحوم الدواجن مغلفة في جو التجميد.

\title{
CONCLUSIONS and RECOMMENDATION
}

\author{
الاستتناجات والتوصيات
}

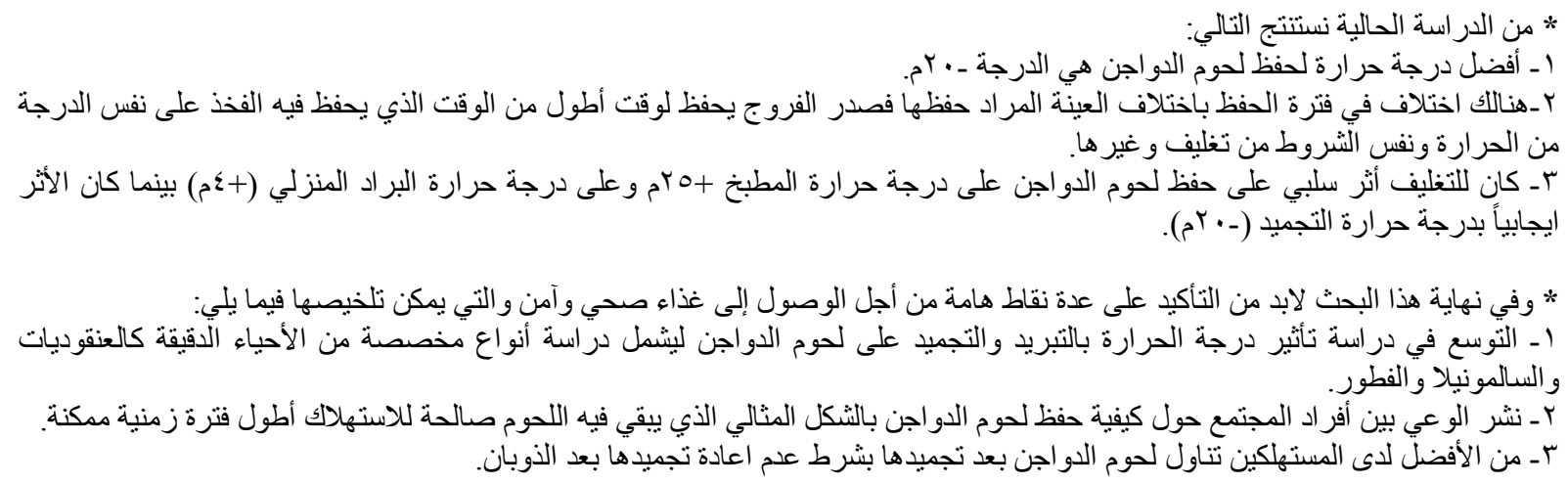

* وفي نهاية هذا البحث لابد من التأكيد على عدة نقاط هامة من أجل الوصول إلى غذاء صحي وآمن و التي يمكن تلخيصها فيما يلي:

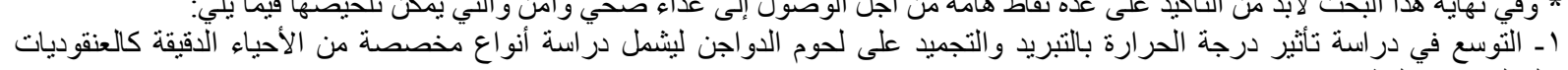

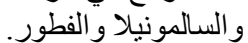

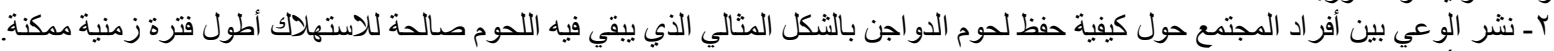

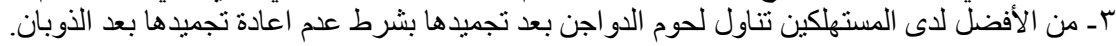

\section{REFERENCE المراجـ}

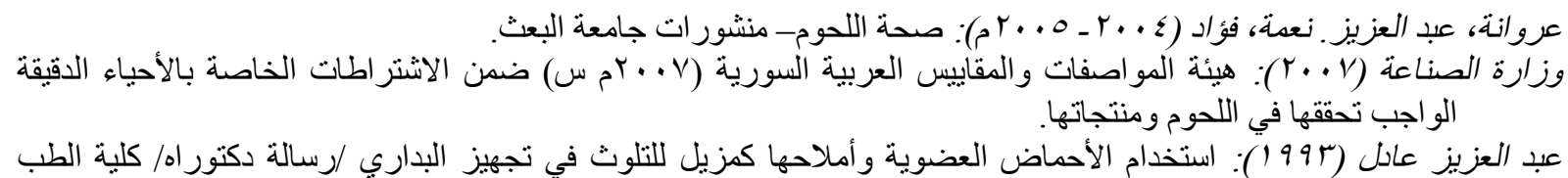
البيطري - جامعة القاهرة.

Al-Jasser, M.S. (2012): Effect of cooling and freezing temperatures on microbial and chemical properties of chicken meat during storage. Journal of Food, Agriculture \& Environment Vol.10 (1): 113-116. 2012.

Anon (2001): US Food and Drug Administration. Center for Food Safety2 and Applied Nutrition. Office of Premarket Approval. GRAS Notices. <http:/vm.cfsan.fda.gov>.

Aymerich, M.; Garriga, J.; Ylla, J.; Vallier, J.M. and Monfort, M. Hugas (2000): Application of enterocins as biopreservatives against Listeria innocua in meat products. Journal of Food Protection, 63, 721-726.

Ashgar, A.; LIN, C.F.; Gray, J.I.; Buckley, D.J.; Boran, A.M. and Flegal, C.J. (1990): Effects of dietary oils and a tocopherol supplementation on membrane lipid oxidation in broiler meat. J. Food Sci. 55: 46-50.

Bilgilisf (2002): Poultry meat processing and marketing \pm what does the future hold?; Poultry International, September, $12 \pm 22$.

CUI, Y. and Wootton, R.J. (1988): Effects of ration, temperature and body size on the body composition, energy content and condition of minnow (Phoxinus phoxinus). J. Fish Biol., 32,749-764pp.

Daud, H.B.; McMeekin, T.A. and Olley, J. (1978): Temperature function integration and the development and metabolism of poultry spoilage bacteria. Appl. Environ. Microbrol., 36,6504.

El-Khateib, T.; Abd El-Rahman; H.; Hamdy, M. and Lotfi, A. (1988): Poultry meat products in Egypt "Proximal chemical composition and microbiological quality" Fleischwirtsch. 68, 6, 756-757.

ERICKSON, M. 1997 Lipid oxidation: Flavor and nutritional quality deterioration in frozen foods. In: Quality in frozen food (edited by M. Erickson \& Y-C. Hung). Pp. 141-173. New York, USA: Chapman and Hall

Firstenberg-Eden, R. and Tricarico, M.K. (1983): Impedimetric determination of total, mesophilic and psychrotrophic counts in raw milk. J. Food Sci., 48, 1750-4.

FAO "Animal production and Health paper. Guide lines for slaughter C- FAO (1991): Rome, Italy.

Gracey, J.F. and Collins, D.S. (1992): Meat hygiene $9^{\text {th }}$ Baillier Tindall-London PP 70-160.

Harris, P. and Tall, J. (1994): Rancidity in fish. In: Rancidity in foods (edited by J. Allen\& R. Hamilton). Pp. 256-272. London, UK: Chapman and Hall.

Han, J.H. (2005): Antimicrobial packaging systems. In Jung H. Han3 (Ed.), Innovations in food packaging (pp. 81-107). Amsterdam: Elsevier Academic Press.

Johnston, R.W. and Tompkin, R.B. (1992): Meat and poultry products. "In compendium of methods for the microbiological examination of foods" P. 821-835 publ. American public Health Assoc. "APHA"

Kietzmann, U.; Priebe, K.; Rakou, D. and Reichstein, K. (1969): Seefisch als Lebensmittel.Berlin, p. 368. 
Kotula, K.L. and Pandya, Y. (1995): Bacterial contamination of broiler chickens before scalding. J. Food Protect., 58, 1326-9.

Lee, C.; Howe, J.M.; Carlson, K. and Clark, H.E. (1971): Nitrogen retention of young men fed rice with or without supplementary chicken. Am. J. Clin. Nutr24: 318-323.

Lee, J.I.; Shin, E.H.; Kim, C.R. and Kim, K.H. (1996): Reducing microbial populations on refrigerated pork harms treated with acetic acid. Kr. J. Food Nutr., 9: 484.

Leistner, L. (1991): Hurden. Technologie fur die Herstellung stabiler Fleischerzeugnisse, Mitteilungsblatt der BAFF, Kulmback.

Love, R.M. (1980): The chemical biology of fishes. Academic Press,1l, London,UK,15p.

Lueck, E. (1987): Antimicrobial Food Additivers. Verlag Edition Orient GM 6 H.

Melly, H.F. (2004): Detection of Hormones and Antibiotics in Broiler Meat. Dip. Vet. Med. for master degree in veterinary medicine Sci.

Neuman, M.A. (1983): Sensorische lebensmitteluntersuchung. VEB, Fachbuch verlag Leipzig.

Pegg, R.B. (2004): Curing.in Encyclopedia of Meat Sciences. W.K. Jensen, C. Devine, and M. Dikeman, ed. Elsevier Ltd., Oxford, UK.

Plumb, A.E. (2002): Storage of Mammalian Spermatozoa at Low Temperatures. Prec. Soc. for Study of Fertility, 2: 12-15. 1C50.

Quinn, P.J.; Carter, M.E.; Markey, B. and Carter, G.R. (1999): Clinical veterinary microbiology. Mosby, $3 \mathrm{~d}$. Ed. PP: 95-102.

Rodel, W. (1975): Einstufung poultry sci.vol.59 no.4. fleiserzeugnissen in, leicht verderbliche, und lagerfahige produdte aufgrund des ph. wert and-warent. vet. -med -Diss. F.U. Berlin.

Romans, J.R.; Costello, W.J.; Carlson, C.W.; Greaser, M.L. and Jones, K.W. (2001): The Meat We Eat.14 ${ }^{\text {th }}$ ed.Interstate Publ., Danville, IL.pp.779-887.

Siegmann, O. and Neumann, U. (2005): Kompendiumder Geflugelkrank heiten. Schlutersche Verlag. 6., Aktualisierte und erweiterte Auflage. (2005), S. (68-110).

Sinell, H-J. (1986): Einfuherung in die lebensmittehrygiene. verlag paul parey, Berlin and Hamberg, 1986.

Skandamis, P.N. and Nychas, G.J.E. (2002): Preservation of fresh meat with active and modified atmosphere packaging conditions. International Journal of Food Microbiology, 79, 35-45.

Sotelo, A. and Perez, L. (2003): Nutritive value of chicken and potato mixtures for infant and preschool children feeding. J. Sci. Food. Agric. 83: 1205-1209.

Wirth, F.; Leistner, L. and Rodel, W. (1990): Richtwerte der fleischndogie. Deuscher Fachverlag, 2 Auflag, 1990. 